\title{
Surface processing of stone by water-jet: assessment of the minerals' luster and comparison with traditional technologies
}

\author{
${ }^{1}$ Department of Civil, Environmental Engineering and Architecture, University of Cagliari, Cagliari 09124, Italy; *Corresponding author, \\ E-mail: ncareddu@unica.it \\ ${ }^{2}$ Environmental Geology and Geoengineering Institute of CNR (IGAG), Section of Cagliari, Cagliari 09123, Italy
}

(Received: January 4, 2017; Revised accepted: June 6, 2017)

http://dx.doi.org/10.18814/epiiugs/2017/v40i4/017031

Natural granite stones play an important role in construction and contemporary design because they are often used for cladding, flooring and generally for street decor. Luster is one of the features which are worth focussing on in order to determine where and how exactly natural stones should be used. Luster is directly related to the aesthetic features of the stone. It is not easily assessed due to the lack of economical instruments as well as standards. The objective of this study is to determine and analyze luster appearing on rough stone surface obtained using different surface finishing methods. For this purpose, a granite with a finish obtained using traditional technologies as well as a varied water-jet technique is studied. Image processing of the specimen are used to assess the luster of each mineral type in relation to the surface finishing technology. The correlations between operating parameters with luster are studied. The variations in the percentage of shiny crystals are also determined. The results of these tests indicate that water-jet technology further enhance the luster more than the competing technologies. Finally, the proposed method for the assessment of the percentage of shiny crystals on a rough stone surface has proven effective.

\section{Introduction}

Natural stone has been widely used over the centuries for construction purposes not only because of its incomparable aesthetic qualities, but also for its strength, durability, and wide availability (Careddu, 2012).

Polished stone surfaces have always been in demand and still continue to be preferred over other types of surface processed stone (PaixãoBarradas et al., 2013). This preference is due to the fact that polishing is the stage when the surface becomes shiny reflective (glossy) and mirroring. With this treatment, the material reaches its maximum definition of veining, pattern and grain, its greatest chromatics enhancement (colour and depth) and a high degree of protection in different ways, i.e., against the risk of oil stains (Primavori, 2010).
However, contemporary stone architecture has encouraged the use of stone slabs with rough (or, better, "rustic") surfaces, especially for external cladding/facing, paving/flooring, street furnishing and exterior design. Rustic-looking treatments now account for approximately $30 \%$ of total stone surface treatments.

The reasons for such popularity can be found in factors linked to fashion (novelty, attractiveness and colour), practicality and safety (no-slip surfaces) and economics. With regard to the economics, this trend encourages the use of lower-quality stone materials (for example, slabs with defects or varied colour) or those which are hard to polish.

Flame-finishing machines and bush-hammering machines are the machines most commonly used for this finish, although these technologies have various technical disadvantages relating to the limits of the slab thickness and the stone type (Careddu, 2010). Other traditional technologies are: sand-blasting (used more on marble than on granite) brushing, which gives a gently rough to the stone (often applied after flame-finishing), and acid-treatment, which can be applied only on calcareous stones (Careddu et al., 2007).

However, none of the above-mentioned technologies is able to preserve the original colours of the rock and its minerals, despite giving a rustic feature to stone surface. An advanced technology which can overcome this problem is the water-jet technology, as discussed in detail (Careddu et al., 2005; Careddu, 2006; Careddu, 2010).

Stone surface may have a luster feature produced by each single crystals' ability to reflect the incident light. This feature can be enhanced or undermined depending on the technology used to make rough the stone surface (Sanmartín et al., 2011).

The bibliography relating to stone surface luster is fairly rich in contributions although it mainly takes into consideration the gloss of polished slate (Wright and Rouse, 1993; Bonifazi and Marinelli, 2003); on the contrary, research assessing the luster created by crystals of a rough-finished stone is missing; some studies have been carried out about the colour variation (Benavente et al., 2003; Sousa and Gonçalves, 2012) since colour is one of the most important aesthetic features that influence the suitability of stone for dimension stone production (Saliu, 2008).

The idea is that, although there are ways to measure the amount of light reflected from a surface (i.e., the Light Reflectance Value, used especially by the paint industry), there are no standardized methods 
that measure only that specific portion of light which is reflected by a specific category of crystals. Depending on their natural layout, these crystals reflect a beam of light. The brightness provided by some minerals is definitely a fine aesthetic added value of the ornamental stone with a "rustic" finishing. Moreover, shiny crystals are surely of great importance for visually impaired people.

With this research the authors suggest a method of both quantitative and qualitative evaluation aiming to assess the differences in mineral luster depending on the finishing technology adopted.

\section{Light, Luster and Related Mineral Properties}

The term luster refers to the general appearance of a mineral surface in reflected light (Klein, 2002).

As there are no specific standards on determination of specular gloss referring to dimension stone sector, natural stone operators refer to EN ISO 2813 (1999) and EN 13722 (2004), which are widely applied in the paper, paints, metals, plastic and ceramic sectors; these standards require the use of a specific instrument (gloss meter). This kind of instrument is currently used in stone polishing assessment (Erdogan, 2000; Ozcelik et al., 2012); glossmeter measures light reflected from a surface illuminated and measured at equal but opposite angles. An increase in surface roughness generally results in reduced gloss (Yavuz et al., 2011).

On the other hand, neither technology nor legislation establishes how to assess the amount of light reflected by the single crystals of a stone slab which has been treated to become uneven and irregular looking, by using a simple, moderately priced method. The present study attempts to offer a solution to this problem.

The minerals can be very shiny, little shiny or opaque. When minerals are well crystallized you can say they are almost all shiny. The luster firstly depends on the perfection of the mineral surfaces, which must be flat and with no stria, then by the chemical composition and, same composition, by the mineral structure (Grill, 1963).

Chemical composition and structure affect the refractive index: the higher the index the greater the reflection, i.e., the amount of light that reaches the eye of the viewer.

There are different types of luster: vitreous luster is commonly seen in quartz (Klein, 2002). Pearly luster (iridescent pear-like luster) is typical of mineral surfaces that lie parallel to well-developed cleavage planes (i.e., plagioclase). Greasy luster, instead, results from light scattered by a microscopically uneven surface, similar to a flame-finished stone surface.

When struck by a ray of light, some minerals can produce a number of different colours depending on the angle of the incident light (Klein, 2002). An iridescence (also called "play of colours") is caused by light diffracted and reflected from closely spaced fractures, cleavage planes, twin lamellae, exsolution lamellae, or minute external inclusions in parallel orientation. An example of this phenomenon is found in labradorite stone (commercial name based on the name of the mineral), quarried mainly in Norway, where plagioclases show colours ranging from blue to green or yellow and red. This iridescence, also called labradorescence, is the result of light scattered by extremely fine $(<0.1 \mu \mathrm{m})$ exsolution lamellae.

Commonly, if you hold a piece of stone in your hand (i.e., a gran- ite), you will see that some crystals will bright occasionally when rotating and moving. This phenomenon is caused by those crystals as they reflect sunlight towards your eyes. In fact, the total brightness of a stone surface is directly related to the type of breaking of the minerals.

The cleavage, parting, and fracture of the stone are the typical response of any crystalline material against an external force. The strength of a crystalline material depends on its bonding mechanisms and the presence- or lack- of structural defects. If the strain in the mineral is greater than its overall strength, it will break. Many minerals have planar directions in their structure that are systematically weaker than other directions. This is the result of planes in the crystal structure that are joined by fewer bonds per unit volume than are other planes in the structure, or are joined by weaker bonds.

Cleavage is the tendency of minerals to break into parallel plates along atomic planes. More exactly, it is a reflection of its own internal structure because the strength of chemical bonding is commonly different in different directions within the same structure. This is especially well shown by layer structures (such as the various mica types, $\mathrm{K}$-feldspars and also graphite) in which the bonding within layers is very strong despite being a lot weaker in between layers. These structures have a perfect cleavage which is parallel to the layering.

Cleavage is completely absent in some minerals as quartz. This mineral has, in fact, a crystal structure in which the strength of the bonds is approximately the same in all directions; so, their breaking generally will not follow a particular crystallographic direction. More specifically, the quartz breaks following a kind of fracture called conchoidal.

It's very important to stress that not all minerals show cleavage, and only a comparatively few show it in eminent degree, which helps form outstanding diagnostic criteria.

Parting is the way minerals break along plans of structural weakness. The weakness may result from pressure or twinning or exsolution. Parting, unlike cleavage, is not shown by all specimens but only by those that are twinned or have been under adequate pressure. Familiar examples of parting are found in the plagioclases.

\section{Materials}

The Ghiandone granite, commercially known as Rosa Limbara, is quarried near Priatu (Sant'Antonio di Gallura) in northern Sardinia, Italy. Thin section of the natural stone sample was prepared and then was examined under a polarized microscope to determine both the textural features and the petrographic composition of the stone. This is a medium to coarse grained granitoid rock macroscopically featuring the presence of "acorns", centimetres-sized (1 to $8 \mathrm{~cm})$ megacrystals of K-feldspar, both automorphic and xenomorphic; on the scale of the outcropping they show weak orientation. Its ensemble of macro- and microscopic traits refers the rock to the "Lovia Avra" lithotype of the monzonite granites of the Gallura area (Cherchi and Musumeci, 1992), which outcrop extensively in the zone between Calangianus and Priatu.

Some of the physical and mechanical properties and grain size of the natural stone samples are given in Table 1. The physical and mechanical properties were determined by a whole range of laboratory tests, which were carried out in accordance with ISRM (2008). 
Table 1. Stone properties of Rosa Limbara according to UE and ASTM standards

\begin{tabular}{|c|c|c|}
\hline Stone Properties - UE STANDARDS & UNIT & STONE \\
\hline Denomination - UNI EN 12440:2008 & & Ghiandone Rosa Limbara \\
\hline Petrographic denomination - UNI EN 12407:2007 & & Granite \\
\hline Real density - UNI EN 1936:2007 & $\mathrm{kg} / \mathrm{m}^{3}$ & 2,626 \\
\hline Apparent density - UNI EN 1936:2007 & $\mathrm{kg} / \mathrm{m}^{3}$ & 2,658 \\
\hline Total porosity - UNI EN 1936:2007 & $\%$ & 1.20 \\
\hline Open porosity - UNI EN 1936:2007 & $\%$ & 0.90 \\
\hline Water absorption at atmospheric pressure - UNI EN 13755:2008 & $\%$ & 0.30 \\
\hline Flexural strength under concentrated load - UNI EN 12372:2007 & $\mathrm{MPa}$ & 15.10 \\
\hline $\begin{array}{l}\text { Flexural strength under concentrated load (after } 48 \text { freeze-thaw cycles) - UNI EN 12372:2007 } \\
\text { + UNI EN 12371:2003 }\end{array}$ & $\mathrm{MPa}$ & 15.20 \\
\hline Compressive strength - UNI EN 1926:2007 & $\mathrm{MPa}$ & 226 \\
\hline Compressive strength (after 48 freeze-thaw cycles) - UNI EN 1926:2007 + UNI EN 12371:2003 & $\mathrm{MPa}$ & 228 \\
\hline Resistance to ageing by thermal shock - UNI EN 14066:2004 + UNI EN 14146:2005 & $\%$ & $\Delta \mathrm{m}=0.04 ; \Delta \mathrm{E}_{\mathrm{d}}=-17.70$ \\
\hline Abrasion resistance - UNI EN 14157:2005 & $\mathrm{mm}$ & 15.50 \\
\hline Slip resistance by means of the pendulum tester - UNI EN 14231:2004 & & $\begin{array}{l}47 \text { (polished and dry sample) } \\
11 \text { (polished and wet sample) }\end{array}$ \\
\hline Linear thermal expansion coefficient - UNI EN 14581:2005 & $\mu \mathrm{m} / \mathrm{m} /{ }^{\circ} \mathrm{C}$ & 9.48 \\
\hline Breaking load at dowel hole - UNI EN 13364:2003 & $\operatorname{mm}_{\mathrm{kN}(\mathrm{d})}\left(\mathrm{d}_{1}, \mathrm{~b}_{\mathrm{A}}\right)$ & $\begin{array}{c}\mathrm{d}_{1}=9.10 \\
\mathrm{~b}_{\mathrm{A}}=43 \\
\mathrm{~F}=1.78\end{array}$ \\
\hline Knoop hardness - UNI EN 14205:2004 & $\mathrm{MPa}$ & $\begin{array}{c}\mathrm{HK} 25=5,536 ; \mathrm{H} 50=7,259 \\
\text { HK } 75=8.898\end{array}$ \\
\hline Stone Properties - ASTM STANDARDS & UNIT & STONE \\
\hline Bulk specific gravity - C 97 - 02 & $\mathrm{~kg} / \mathrm{dm}^{3}$ & 2.63 \\
\hline Absorption - C 97 - 02 & $\%$ & 0.20 \\
\hline Modulus of rupture - C $99-00$ & $\mathrm{MPa}$ & $\mathrm{R}=16.30$ \\
\hline Flexural strength - C $880-98$ & $\mathrm{MPa}$ & $\sigma=13$ \\
\hline Compressive strength - C 170 - 99 & $\mathrm{MPa}$ & $\mathrm{C}=172$ \\
\hline Abrasion resistance of stone subjected to foot traffic - C 241 - 97 & & $\mathrm{H}_{\mathrm{a}}=38.27$ \\
\hline
\end{tabular}

Different standards (EN and ASTM) were used to evaluate the same properties, because this stone is exported both to U.S.A. and E.U.

There are several reasons why this stone has been chosen. Firstly, the greater size of the crystals, compared with those of other granites, which makes a better assessment of the their luster possible. A second reason lies in the fact that the slabs of Ghiandone are sold with almost all types of surface finishing. Finally, there are countless examples of use in the world of Ghiandone granite, such as the stairs of the Presidential Palace in Turkmenistan, and the cladding of some skyscrapers in Perth (Australia) (R.A.S., 1999) as well as high number of buildings, street paving and urban fabric in many towns of the North Sardinia (Grillo et al., 2009).

\section{Experimental}

Thirteen specimens, having size $10 \mathrm{~cm} \times 10 \mathrm{~cm}$, were obtained from slabs of Ghiandone granite differently finished and used in this study as shown in Figure 1. More exactly stone specimens were processed by bush-hammering (BH), flame-finishing (FF), polishing (P), water-jet finishing and the raw saw-plane surface (SP) due to the slabbing by gangsaw.

With regard to the water-jet finishing, nine specimens were considered, each one obtained by a different combination of operational parameters (as listed in Table 2).

The choice of the specimens finished by abrasive water-jet (AWJ) was made on the basis of aesthetic, technical and economical assessments, already described in previous research (Careddu et al., 2006; Careddu, 2008; Careddu, 2009). It should be noted that AWJ specimens (from 24 to 31 ) shown Figure 1 look similar but they aren't, especially for their different roughness. The specimen finished by pure water jet (PWJ) was included in the study to allow a more complete comparison with the other finishing technologies considered.

These nine specimens were finished by keeping constant the following operational parameters: nozzle diameter $\varnothing_{n}=0.3 \mathrm{~mm}$, water pressure $\mathrm{P}=300 \mathrm{MPa}$ and jet inclination $\gamma=30^{\circ}$ with respect to the 
Table 2. Operating parameters used in surface finishing processes by using water-jet technology

\begin{tabular}{|c|c|c|c|c|c|c|c|}
\hline & $Q_{a}[\mathrm{~g} / \mathrm{min}]$ & $i[\mathrm{~mm}]$ & $\varnothing_{f}[\mathrm{~mm}]$ & $d[\mathrm{~mm}]$ & $v_{t}[\mathrm{~m} / \mathrm{min}]$ & $v_{w}\left[\mathrm{~m}^{2} / \mathrm{h}\right]$ & $S E\left[\mathrm{MJ} / \mathrm{m}^{2}\right]$ \\
\hline PWJ & 0.0 & 5 & 1.0 & 100 & 20 & 6.00 & 19.58 \\
\hline AWJ24 & 202.1 & 15 & 3.0 & 60 & 2 & 1.80 & 65.25 \\
\hline AWJ25 & 202.1 & 10 & 3.0 & 60 & 2 & 1.20 & 97.88 \\
\hline AWJ26 & 202.1 & 21 & 3.0 & 100 & 2 & 2.52 & 46.61 \\
\hline AWJ27 & 202.1 & 12 & 1.4 & 60 & 10 & 7.20 & 16.31 \\
\hline AWJ28 & 202.1 & 10 & 1.4 & 60 & 20 & 12.00 & 9.79 \\
\hline AWJ29 & 202.1 & 15 & 1.4 & 60 & 5 & 4.50 & 26.10 \\
\hline AWJ30 & 202.1 & 10 & 1.4 & 60 & 5 & 3.00 & 39.15 \\
\hline AWJ31 & 90.0 & 5 & 1.4 & 60 & 20 & 6.00 & 19.58 \\
\hline
\end{tabular}
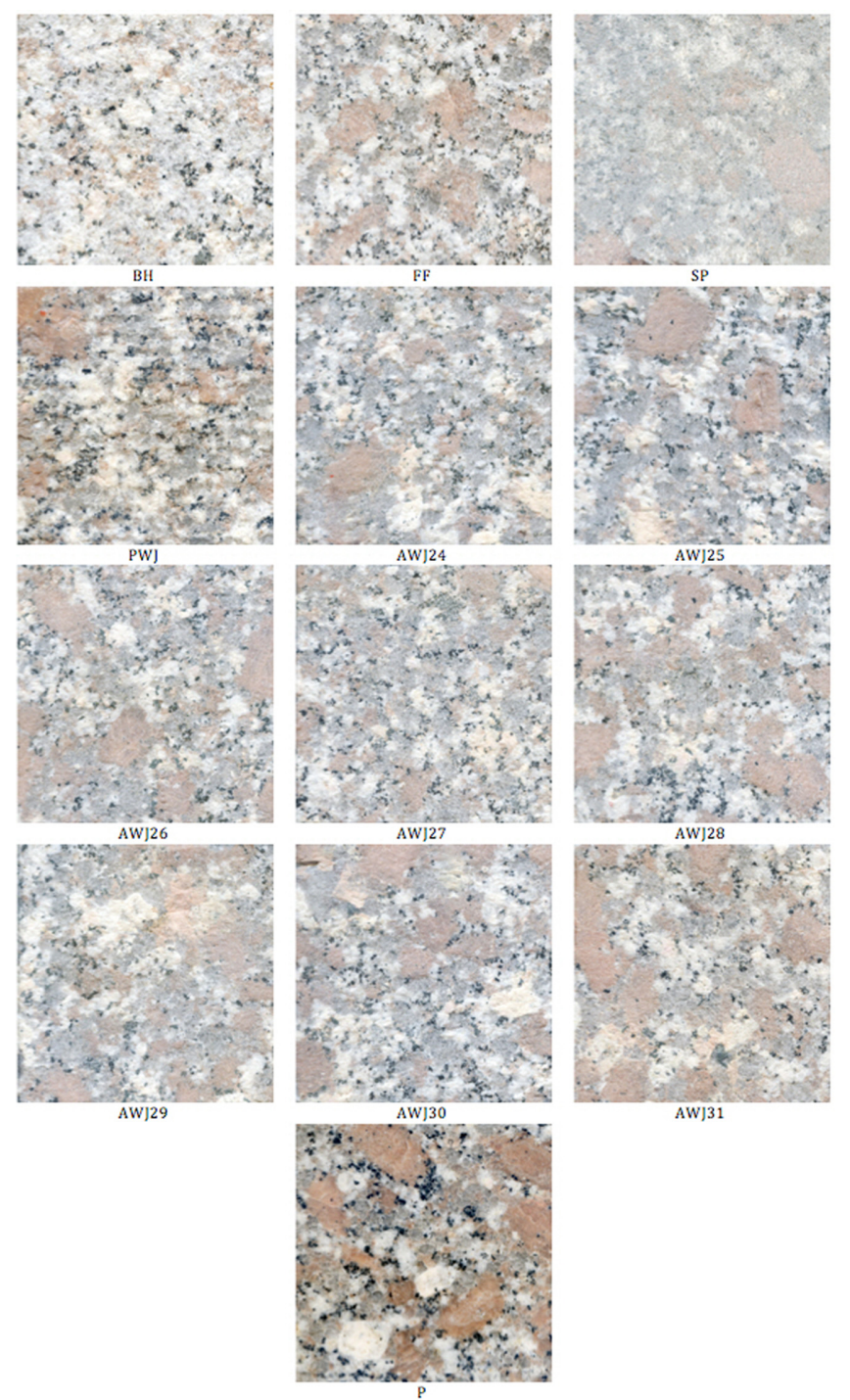

AW] 31

Table 3. Imaging parameters

\begin{tabular}{|c|c|}
\hline Camera parameters & F/22 \\
\hline F-stop & $1 / 20 \mathrm{~s}$ \\
\hline Shutter speed & ISO-1600 \\
\hline Sensitivity & $55 \mathrm{~mm}$ \\
\hline Focal length & none \\
\hline Flash mode & \\
\hline
\end{tabular}

calculated as:

$$
v_{w}=v_{t} \cdot i \frac{60}{1000}\left[\mathrm{~m}^{2} / \mathrm{h}\right]
$$

The surface finishing specific energy $S E$, expressed in $\mathrm{MJ} / \mathrm{m}^{2}$, has been computed by following Careddu et al. (2014).

\section{Images Captures}

The photography studio has been housed in an internal environment completely devoid of outdoor lights that could interfere with the used light source.

A high-lightness LED torch, with a luminous flux of $200 \mathrm{~lm}$, was used as a light source. The image capture has been carried out with a digital camera Canon EOS 400D. Imaging parameters were chosen after several preliminary tests and are summarized in Table 3.

The mutual positions of the specimen, light source and digital cam-

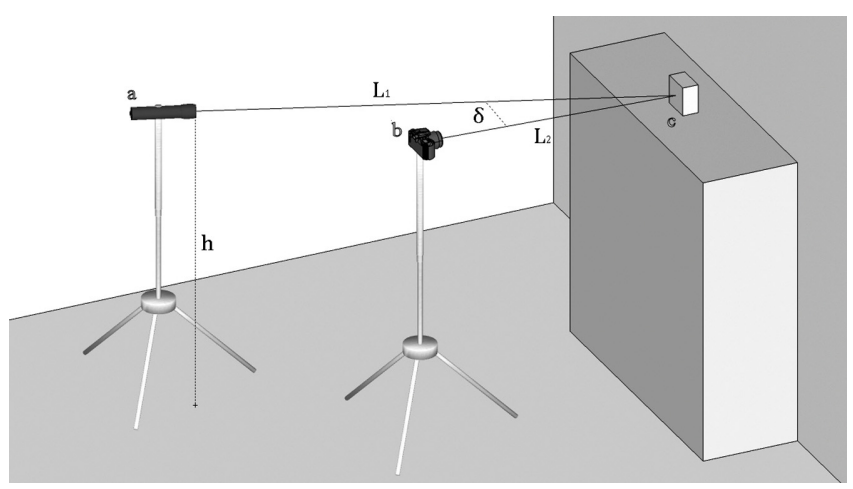

Figure 2. Photo studio 3-D view; LED torch (a), digital camera (b) and stone sample (c).

\section{Figure 1. The thirteen specimens studied.}

horizontal plane.

Variable parameters were: mass flow rate of abrasive $Q_{a}$, pass spacing $i$ (distance between water-jet parallel passes), focusing tube diameter $\varnothing_{f}$, stand-off distance $d$ and water-jet travel speed $v_{t}$.

From the above parameters, the surface finishing net velocity $v_{w}$ is 


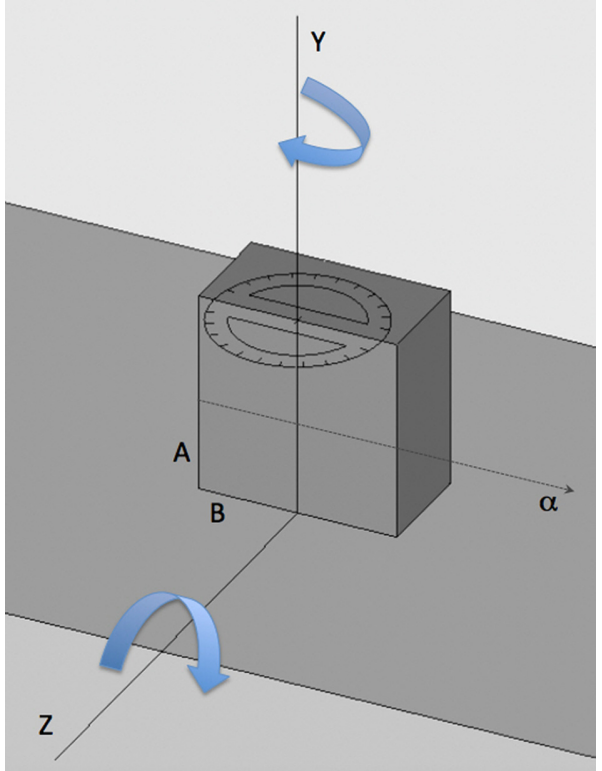

Figure 3. Image capturing method.

era are shown in Figure 2, where $\mathrm{L}_{1}=2.00 \mathrm{~m}, \mathrm{~L}_{2}=0.62 \mathrm{~m}, \mathrm{~h}=1.22 \mathrm{~m}$ (same altitude for LED torch, digital camera and specimen), $\delta=22^{\circ}$.
As shown in Figure 3, each specimen was rotated clockwise (around the vertical axis $\mathrm{Y}$ ) so as to capture an image every $5^{\circ}$ starting from $0^{\circ}$ (parallel to the camera audition) up to $180^{\circ}$; then it was rotated on itself (around the horizontal axis Z) by $90^{\circ}$ and the previous operation was repeated. 74 images were acquired for each audition.

The side which is perpendicular to the support base of the specimen on the left of the camera was named " $\mathrm{A}$ " for conventional purposes, whilst " $\mathrm{B}$ " was the side of the floor (and therefore perpendicular to side "A"). Similarly, two directions were named " $\alpha$ " and " $\beta$ ", both of them respectively perpendicular (lying on the face the specimen) to sides "A" and "B".

Regarding the bush-hammered, flame-finished, polished and sawplane specimens, the above-mentioned convention for the choice of A and $\mathrm{B}$ is indifferent. On the contrary, those the samples processed by water-jet technology, have named " $A$ " as the side from where the surface machining started.

\section{Image Processing}

Despite having a constant average mineralogical composition, typical of the area where Rosa Limbara is quarried, each specimen shows a small difference in percentage distribution of mineralogical species. Therefore it was necessary to quantify, for each specimen, the areas

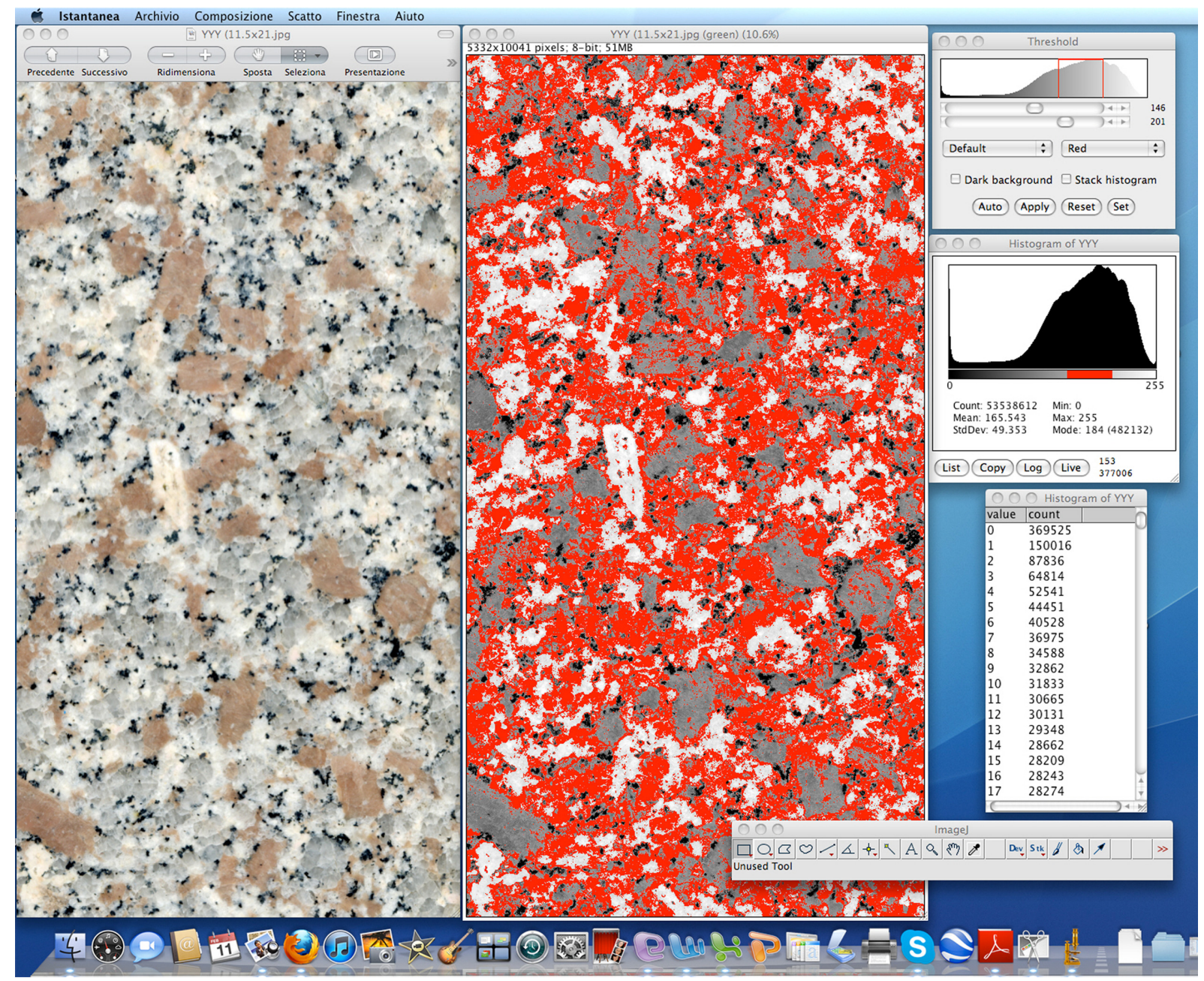

Figure 4. Image processing by using software ImageJ $1.47 v$. 
where minerals were visible on the surface; this stage was strategic because the acquired data were then compared to the overall areas of shiny minerals.

For this purpose we used the image analysis software ImageJ $1.47 \mathrm{v}$, developed by the National Institutes of Health (NIH), USA. ImageJ $1.47 \mathrm{v}$ allows calculating both area and statistics based on pixels value in relation to the user-selected regions (Fig. 4).

The images used for this kind of processing were acquired through high-definition scanning, following the same procedure already used in Akkoyun et al. (2013) and Careddu and Marras (2013).

CAD software was used for both tracking and measuring areas of all shiny mineral areas for each image acquired as described in 4.1 (Fig. 5). Finally, for each mineral species $m$ of every specimen $n$, the following ratio was calculated:

$$
\pi_{m, n}=\frac{S_{m, n}}{S_{m, n}}
$$

that is the fraction of the total area $s$ of mineral $m$ that was shiny and the total area $S$ of the same mineral that appeared on the surface of the $n^{\text {th }}$ specimen. These ratios were firstly calculated by separating sides A from $B$; the total value was then calculated by the sum of the two previous values (A and $\mathrm{B}$ ); as special care was taken to avoid including the same shiny crystal again and again.

Finally, for each specimen, the total percentage $\Pi$ of shiny minerals was calculated according to the equation:

$$
\Pi_{n}=\frac{\sum_{m} s_{m, n}}{\sum_{m} S_{m, n}} .
$$

It should be noted that, given the size of the specimens, $\sum_{m} S_{m, n}=100 \mathrm{~cm}^{2}$.

\section{Results and Discussion}

\section{General Considerations}

No substantial differences in percentage of shiny minerals between directions $\alpha$ and $\beta$ with regard to the flame-finished, bush-hammered and saw-plane specimens was recorded. This means that the crystals breaking happens at random. On the contrary, the following differences are observed in the samples processed by water-jet:

- in general, all specimens finished with the use of abrasive waterjet have a greater percentage of shiny surface along the direction $\alpha$ than $\beta$. These differences are mainly due to the reaction of K-feldspars which are likely to be broken more easily along the cleavage planes; as expected, these breakages occur more easily when cleavage planes are parallel to the direction of the water-jet;

- in the case of the sample finished by pure water-jet, the difference in results observed along the two directions is mainly linked to the inner feature of quartz. In fact, quartz is better excavated also because of its inner fragility and lower impact strength, enhanced by unfavourable deformability properties. The modulus of elasticity of quartz ( $96 \mathrm{GPa}$ ) is significantly higher than those of K-feldspar (63 GPa), plagioclase (75.1 GPa) and biotite (69.7 GPa) (Agus et al., 1991). Therefore quartz is more stressed under the PWJ impact than the other minerals, which are able to relieve partially the load through deformation.

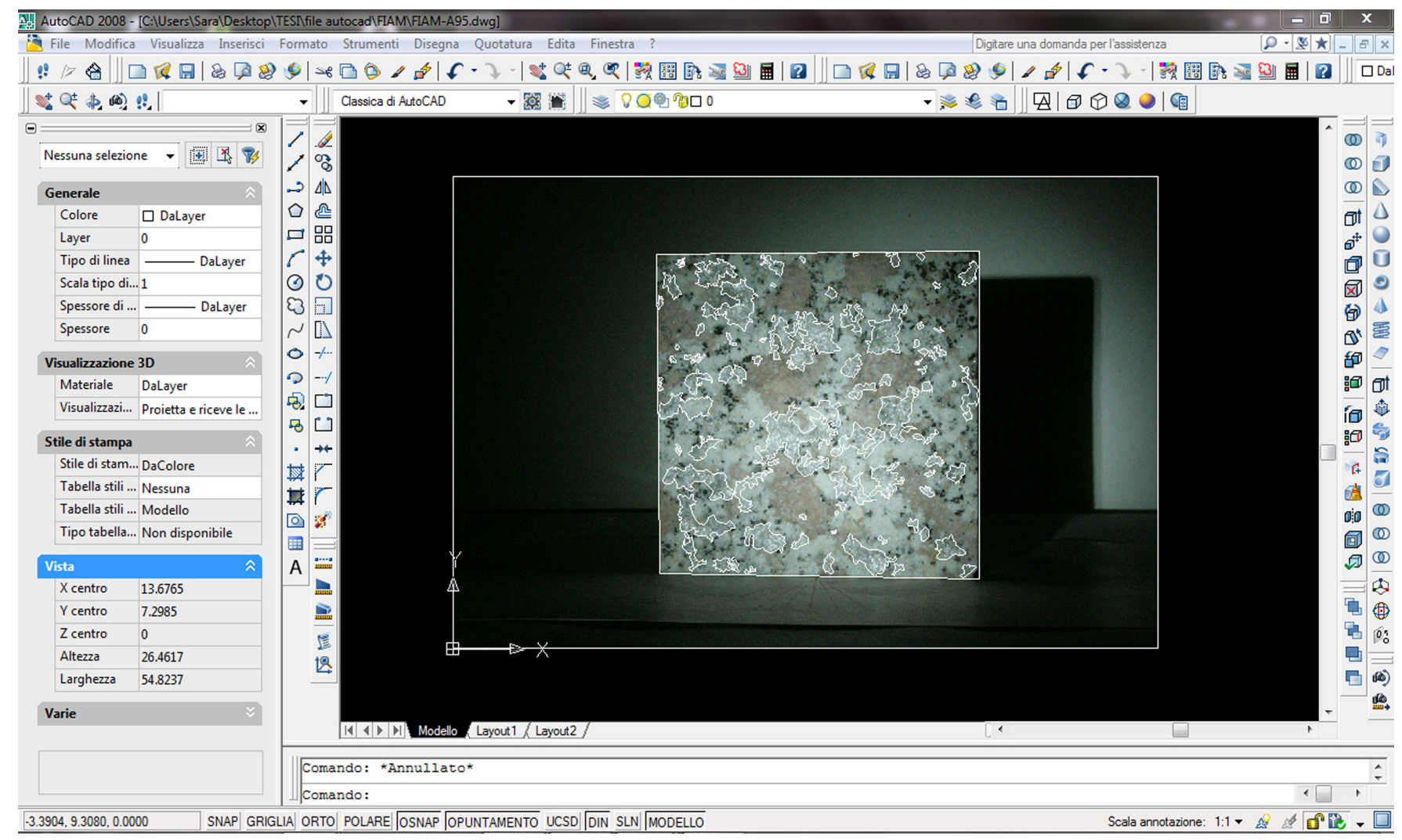

Figure 5. CAD tracking of shiny minerals areas. 


\section{Correlations between Water-jet Parameters and Percentage of Shiny Crystals}

Mass flow-rate of abrasive

Mass flow-rate of abrasive $Q_{a}$ does not seem to affect, in general, the percentage of whole shiny surface. On the contrary, quartz seems to be affected by the increase of this parameter: when the $Q_{a}$ increases the percentage of shiny quartz decreases (as shown in Fig. 6). Also the percentage of plagioclase shiny crystals decreases with the increasing of $Q_{a}$, but less than quartz. The percentage shiny crystals of both Kfeldspar and biotite is not affected by $Q_{a}$.

\section{Pass spacing}

The pass spacing $i$ seems to affect more on the percentage of shiny crystals (Fig. 7) than the previous parameter. All minerals show a decreasing trend of shiny crystals percentage as $i$ increases. This is especially noticeable in quartz, especially when it is linked to the increase of $Q_{a}$ as shown in Figure 8.

\section{Focusing tube diameter}

The general trend is fairly constant for all minerals, as the focusing tube diameter $\varnothing_{f}$ increases, the percentage of specimens' shiny crystals decreases. This is much more evident in quartz than other minerals (Fig. 9).

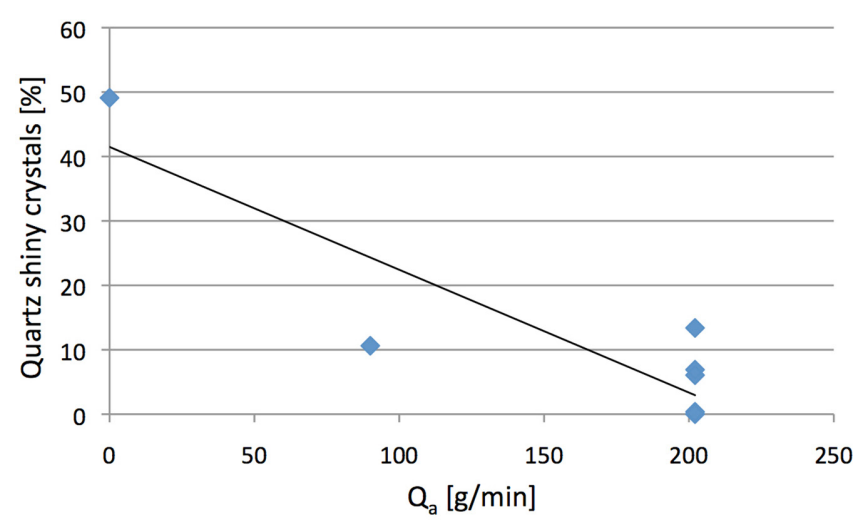

Figure 6. Correlation between percentage of shiny quartz crystals and mass flow-rate of abrasive $\left(R^{2}=0.79\right)$.

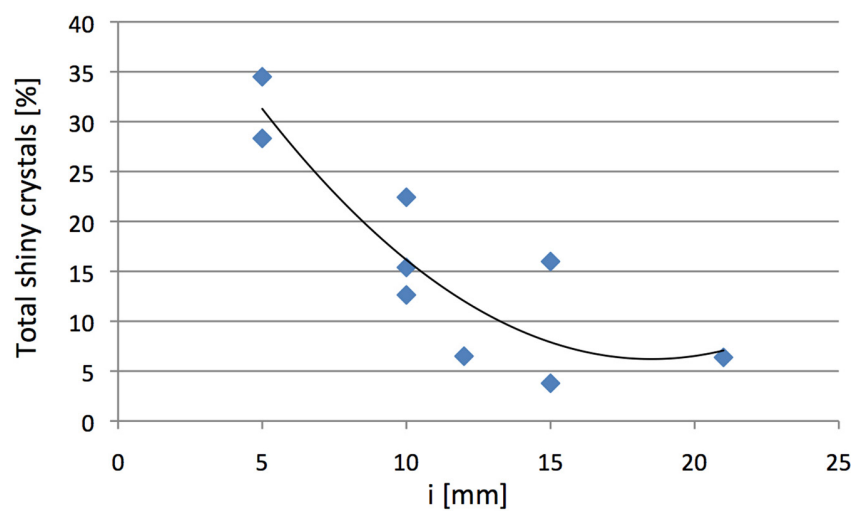

Figure 7. Correlation between percentage of specimen's shiny crystals and pass spacing $\left(R^{2}=0.79\right)$.

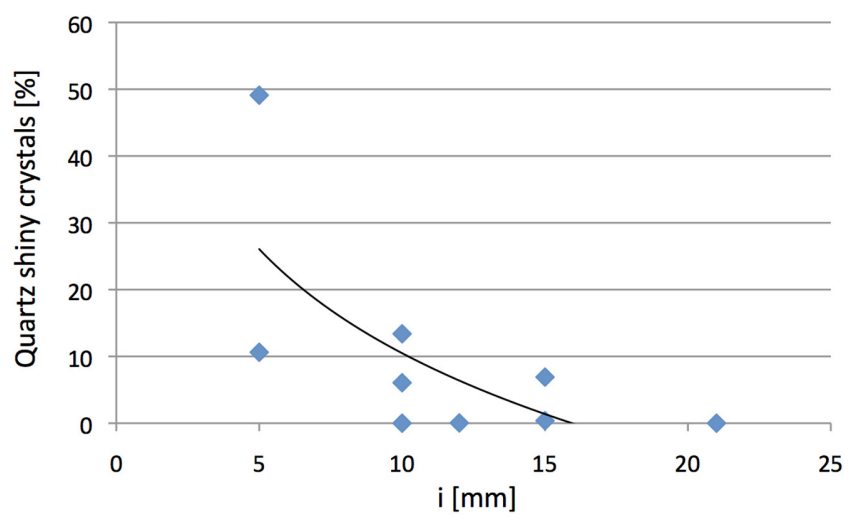

Figure 8. Correlation between percentage of quartz shiny crystals and pass spacing $\left(R^{2}=0.48\right)$.

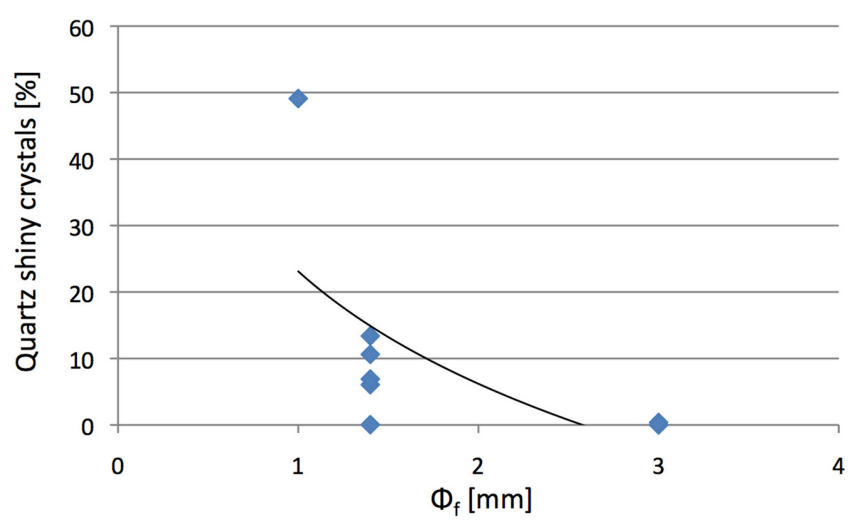

Figure 9. Correlation between percentage of quartz shiny crystals and focusing tube diameter $\left(R^{2}=0.44\right)$.

\section{Stand-off distance}

The stand-off distance $d$ does not play a key role in the variation of percentage of shiny crystals. Only the K-feldspar appears to be slightly affected in negative way when $d$ increases.

\section{Water-jet travel speed}

When the water-jet travel speed $v_{t}$ increases there is generally a percentage increase in specimens shiny crystals (Fig. 10). This result is related to the fact that with increasing $v_{t}$, the jet has a lower residence time on the single crystals that are then mostly broken along the cleavage planes.

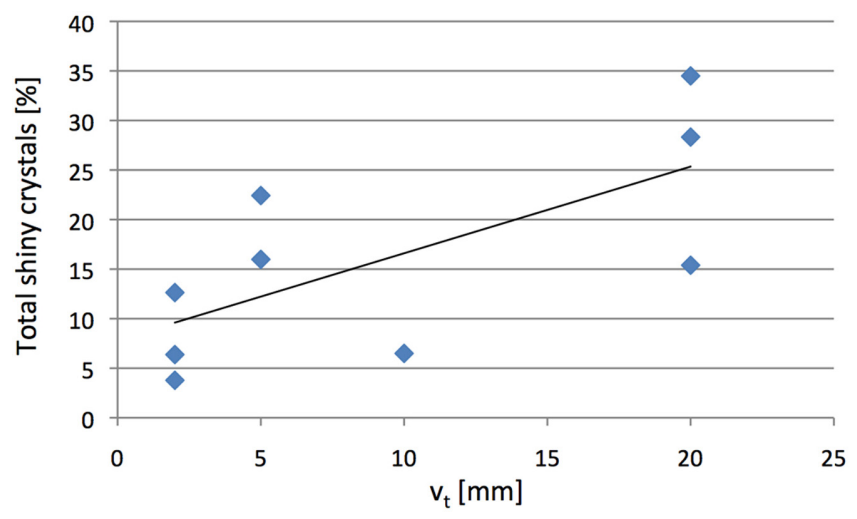

Figure 10. Correlation between percentage of specimen's shiny crystals and water-jet travel speed $\left(R^{2}=0.47\right)$. 


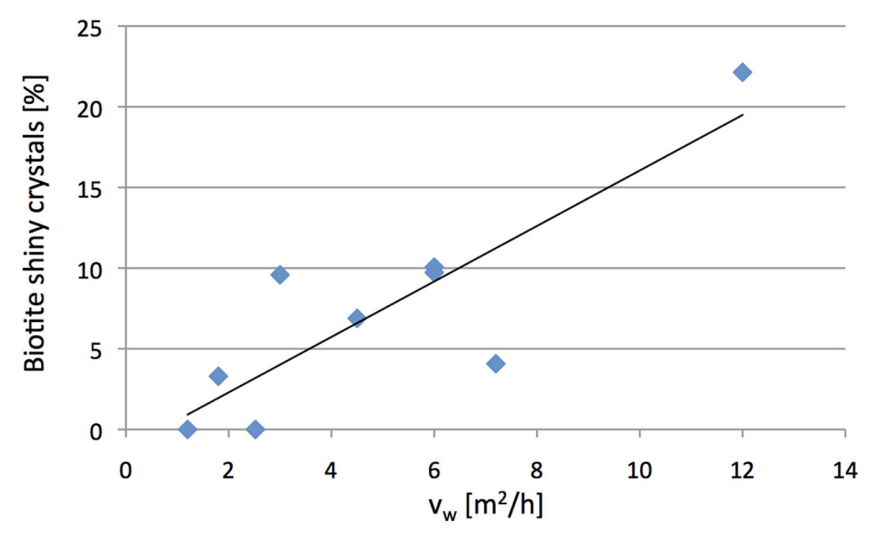

Figure 11. Correlation between percentage of biotite shiny crystals and surface finishing net velocity $\left(R^{2}=0.72\right)$.

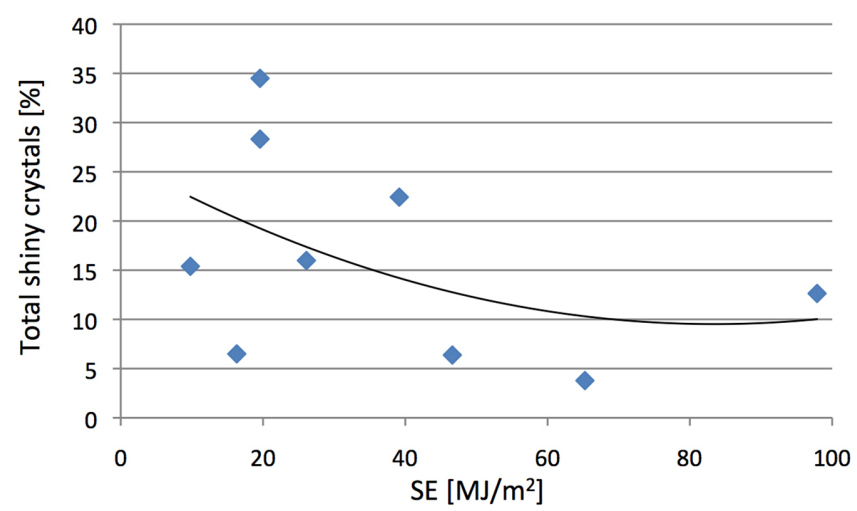

Figure 12. Correlation between percentage of specimens' shiny crystals and surface finishing specific energy $\left(R^{2}=0.19\right)$.

\section{Surface finishing velocity (net)}

The surface finishing net velocity $v_{w}$ is a real technical parameter aimed to evaluate the machining process, in fact $v_{w}$ answers the following question: "how many square meters can be finished in an hour?". It seems that $v_{w}$ affect the specimens' percentage of shiny crystals as it increases. This is noticeable especially in biotite: this mineral increases its percentage of shiny crystals when $v_{w}$ increases (as shown in Fig. 11).

\section{Surface finishing specific energy}

The surface finishing specific energy $S E$ can be considered as an economic parameter for water-jet technology (Bortolussi et al., 1996): the greater the specific energy the greater unit cost of machining.

The general trend (Fig. 12) for all minerals shows a clear decrease of the percentage of specimens shiny crystals alongside the increase of $S E$ (especially in quartz and plagioclase). This interesting result suggests that it may not be necessary to "invest" too much energy to have shiny surfaces: good results with shiny surfaces may now be obtained at a lower budget (lower $S E$ ).

\section{Considerations on percentages of shiny crystals depend- ing on surface treating technology}

The diagram bar in Figure 13 shows how the percentage of shiny crystals varies depending on the type of surface treatment applied on the stone specimen. Percentage of shiny crystals of both each mineral and whole specimen itself were considered.

The polished specimen shows a percentage of shiny surfaces little more than $7 \%$ (referred to the whole surface), which is very low. This is due to the fact that all residual pores are occluded and the surface becomes reflective and mirroring (Primavori, 2010) during polishing,

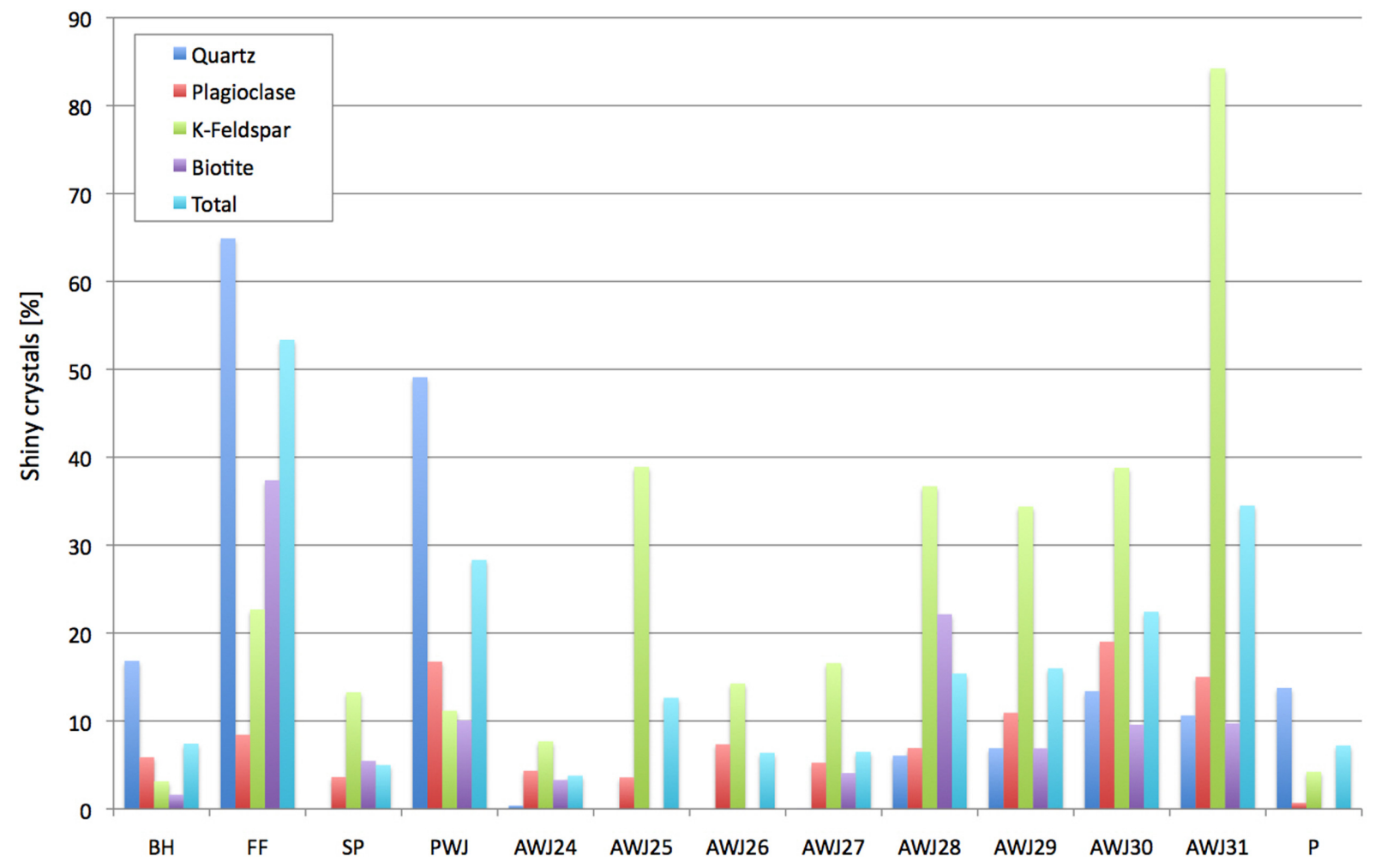

Figure 13. Percentage of shiny crystals for each specimen. 
which is the final stage of smoothing. Therefore, all minerals lie on the specimen surface at the same level, which makes it very difficult to obtain luster.

The saw-plane specimen shows a percentage of shiny surface lower than $5 \%$ and we couldn't expect anything different than that. The slabbing was made using a traditional granite pendulum gangsaw, which utilized a mixture of water-lime-steel shot during sawing. From a chromatic point of view, the result is an almost colourless surface, with some mildly shining K-feldspar crystal, where cleavage planes were parallel to the direction of the blade.

Because of the nature of percussion process (the surface finishing is made through a continuous impact of a bush-hammer), the bush-hammered specimen shows a succession of dents and rises, with the former always in the form of little white dots and similar to orange rind in look and roughness. The percentage of shiny surface is less than $7.5 \%$.

The traditional technology used in surface processing, which can be compared with water-jet machining in relation to its percentage of shiny crystals, is the flame-finishing.

The flame-finished specimen, in fact, shows a percentage of shiny surface above $50 \%$, due particularly to quartz (almost $65 \%$ ). This result resembles what obtained on specimen finished by PWJ technology. In both cases the quartz is enhanced by the processes, with the difference that FF also seems to highlight the biotite. For the same considerations mentioned in 2 (conchoidal breaking), we have to point out that quartz crystals reach maximum luster if placed in front position with respect to the observer.

Unfortunately the WJP finishing technology does not allow a uniform machining of granite Ghiandone, as already stressed by Careddu (2009), since the K-feldspars are difficult to be machined.

On the other hand the FF "dampens" the plagioclases (only $8.43 \%$ of them shine) and the main number of K-feldspars. Abrasive waterjet machining, on the contrary, enhances the latter, which has produced an average percentage of shiny K-feldspar crystals around $40 \%$ with a peak that come close to $85 \%$. In fact, thanks to their mineralogical structure, K-feldspars tend to split more easily if hit by a water-jet added with abrasive particles, especially when the cleavage planes of this mineral tend to be parallel to the direction of the jet. On the contrary, the quartz is not particularly enhanced by AWJ finishing process.

\section{Conclusions}

The results highlighted by this study quantify the luster brilliance shown by the all minerals which the considered stone is made of, depending on the type of surface processing used. Those findings were so far known only in a qualitative way.

The study shows that water-jet technology, has remarkable aesthetic advantages when compared to the traditional technologies of "rustic" surface processing here examined: crystals show peculiar luster, which is variable depending on the angle and intensity of the light that hits them, keeping intact both their chromatic and mechanic features, while presenting a rough appearance.

There were some similarities between the flame-finishing and PWJ because they both emphasize in especially the quartz but, while the first dampens the colours of the other minerals and deeply alters their structure, PWJ finish does not alter the structure or the chromatics. The best aesthetic results are achieved using AWJ particularly at a lower $S E$, although high correlation between the AWJ operative parameters and the percentage of shiny crystals weren't found. The proposed assessment method for the luster of a rough stone surface is proved effective. However, it should be kept on mind that a different typology of granite is expected to give different results in terms of percentage of shiny crystals.

\section{Acknowledgements}

The authors wish thank to S.G.E. Graniti s.r.l. Company for having provided the stone slabs used in this research and dr. Stefania Puxeddu for her linguistic support. This study has been carried out as part of a project promoted with the support of IGAG-CNR.

\section{References}

Agus, M., Bortolussi, A., Ciccu, R., Manca, P.P., and Massacci, G., 1991, Jet impingement tests on mineral crystals (abs.): Proceedings of the $1^{\text {st }}$ Asian Conference on Recent Advances in Jetting Technology, Singapore, 1991, pp. 1-9.

Akkoyun, O., Careddu, N., and Marras, G., 2013, An investigation of colour properties of Orosei limestones (Italy) by using computer program: Key Engineering Materials, v. 548, p. 173-182.

Benavente, D., Martínez-Verdú, F., Bernabeu, A., Viqueira, V., Fort, R., García del Cura, M.A., Illueca. C., and Ordóñez, S., 2003, Influence of surface roughness on color changes in building stones: Color Research and Application, v. 28, no. 5, pp. 343-351.

Bonifazi, G., and Marinelli, M., 2003, Ornamental stone finished product aesthetic inspection and characterization through a digital spectrophotometric approach (abs.): Proceedings of SPIE 5011, Machine vision applications in industrial inspection XI, Santa Clara, 2003, pp. 243250.

Bortolussi, A., Ciccu, R., Fiamminghi, A., Agus, M., and Careddu, N., 1996, Deep slotting tests with waterjet on a japanese granite (abs.): Proceedings of the $5^{\text {th }}$ International Symposium on Mine Planning and Equipment Selection. São Paulo, 1996, pp. 337-343.

Careddu, N., 2006, Developments in the surface finishing of ornamental rocks by high-pressure water jet without abrasive and proposal for an official name for the process: Diamante - Applicazioni e Tecnologia, $n$. 46 (suppl.), pp. 65-77; also printed in: Diamante - Applicazioni e Tecnologia, no. 47, pp. 65-77.

Careddu, N., 2008, Granite surface processing by abrasive water-jet technology: Proceedings of the $2^{\text {nd }}$ International Congress on Dimension Stones, Carrara, 2008, pp. 169-174.

Careddu, N., 2009, Working granite surfaces with a high-pressure waterjet: a comparison of abrasives and economic considerations: Marmomacchine, no. 208, pp. 50-68.

Careddu, N., 2010, Surface treatment of ornamental stones by high-pressure, water-jet technology: Mining Engineering, v. 62, no. 7, pp. 44-50

Careddu, N., 2012, Rough surface finishing of stone-faced sandwich panels using high pressure waterjet: Journal of Materials in Civil Engineering, v. 24, no. 7, pp. 907-915.

Careddu, N., Akkoyun, O., Medda, P., and Tilocca, C., 2014, Technicaleconomic assessment of stone slabs surface finishing using water jet technology: International Journal of Advanced Manufacturing Technology, v. 71, no. 9-12, pp. 1991-2001.

Careddu, N., Ciccu, R., and Costa, G., 2005, Applicazione della tecnologia water-jet alla lavorazione superficiale dei graniti: Marmomacchine 
Classic, no. 184 , pp. 218-238. (in Italian)

Careddu, N., Ciccu, R., Costa, G., Medda, R., Naitza, S., and Primavori, P., 2007, Working the surfaces of non-flammable ornamental rocks with water-jets technology (Part one): Marmomacchine Classic, no. 196, pp. 164-187.

Careddu, N., and Marras, G., 2013, The effects of solar UV radiation on the gloss values of polished stone surfaces: Construction and Building Materials, v. 49, pp. 828-834.

Cherchi, G.P., and Musumeci, G., 1992, Il complesso granitoide della Sardegna settentrionale. in Carmignani, L., Pertusati, C., and Barca, S. (eds.), Struttura della Catena Ercinica in Sardegna - Guida All'Escursione: Pacini Pub., Pisa, pp. 157-163. (in Italian)

EN ISO 2813, 1999, Paints and varnishes - determination of specular gloss of non-metallic paint films at $20^{\circ}, 60^{\circ}$ and $85^{\circ}$, April, 1999 .

EN 13722, 2004, Furniture - Assessment of the surface gloss, July, 2004.

Erdogan, M., 2000, Measurement of polished rock surface brightness by image analysis method: Engineering Geology, v. 57, p. 65-72.

Grill, E., 1963, Minerali industriali e minerali delle rocce: determinazioni al microscopio e per via fisico-chimica: Ulrico Hoepli Pub., Milano, 874 p. (in Italian)

Grillo, S., Mocci, S., Pia, G., Spanu, N., and Tuveri, L., 2009, Il materiale litico. in Sanna, U., and Atzeni, C. (eds.), Il Manuale Tematico della Pietra: Itaca Press, pp. 13-23. (in Italian)

ISRM, 2008, The complete ISRM suggested methods for rock characterization testing and monitoring: 1974-2006. in Ulusay, R., and Hudson, J.A. (eds.), Commission on Testing Methods: International Society for Rock Mechanics, Ankara, ISRM Turkish National Group Pub., 628 p.

Klein, C., 2002, The $22^{\text {nd }}$ Edition of the Manual of Mineral Science (after James D. Dana): Wiley, New York, 641 p.

Ozcelik, Y., Careddu, N., and Yilmazkaya, E., 2012, The effects of freezethaw cycles on the gloss values of polished stone surfaces: Cold Region Science and Technology, v. 82, p. 49-55.

Paixão-Barradas, S., Ortuño, B.H., and Agudo, B.V., 2013, Design of more competitive products in natural stone: what Companies are offering and what the market is looking for: Key Engineering Materials, n. 548, p. 304-316.

Primavori, P., 2010, Surface finishes on stone materials. in Assomarmomacchine (eds.), Directory 2010: Marmomacchine Servizi s.r.l. Pub., Milano, pp. 70-165.

R.A.S., 1999, Guida alle pietre ornamentali della Sardegna, Regione Autonoma Sardegna: Assessorato Industria Pub., 130 p. (in italian)

Saliu, A.M., 2008, The development of a new approach to colour characterization in dimension stone mining: International Journal of Applied Engineering Research, v. 3, no. 8, pp. 1135-1140.

Sanmartín, P., Silva, B., and Prieto, B., 2011, Effect of surface finish on roughness, color, and gloss of ornamental granites: Journal of Materials in Civil Engineering, v. 23, pp. 1239-1248.

Sousa, L.M.O., and Gonçalves, B.M.M., 2012, Color assessment of granitic rocks and implications for their ornamental utilization: Color Research and Application, v. 37, no. 5, pp. 375-383.

Wright, D.N., and Rouse, C., 1993, Stone polishing measurement of surface finish: Industrial Diamond Review, v. 53, no. 1, pp. 10-13.

Yavuz, H., Ozkahraman, T., and Demirdag, S., 2011, Polishing experiments on surface quality of building stone tiles: Construction and Building Materials, v. 25, pp. 1707-1711.

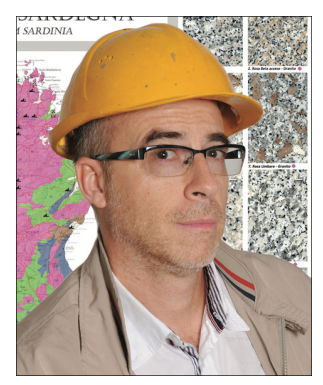

Nicola Careddu received his degree in Mining Engineering and a $\mathrm{PhD}$ degree in Geoengineering at the University of Cagliari, respectively in 1995 and 1999. Since 2002, he has been assistant professor at the University of Cagliari where he has supervised more than 50 academic theses, ranging from B.Eng. to PhD. Since 2005 he has taught the courses: "Surface Mining" and "Drilling Techniques"; he became Senior Researcher in 2011. He has published more than 50 scientific papers in international journals and conference proceedings and currently referees international journals. He is both member of the Scientific Committee of Global Stone Congress and of the HSTG (Heritage Stone Task Group) since 2012. He participates in the Scientific Committee of several scientific/technic journals both nationally and internationally. His subjects of research mainly concern the area of Dimension Stone and mining engineering topics.

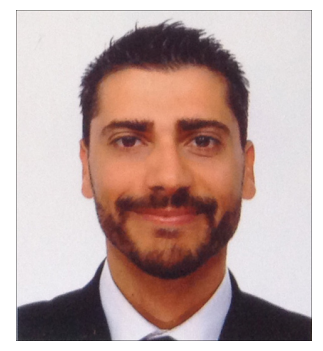

Alessandro Mazzella achieved Master's Degree in Environmental Engineering specializing in "Geo-resources Research and Evaluation"; $\mathrm{PhD}$ in Geo-Engineering and Environmental Technologies; Research Assistant at Institute of Geo-Engineering and Environmental Geology of Italian National Research Council (CNR); Lecturer of "Geostatistics and Geographic Information Systems" at University of Cagliari; freelance and consultant in Environmental and Mining Engineering.

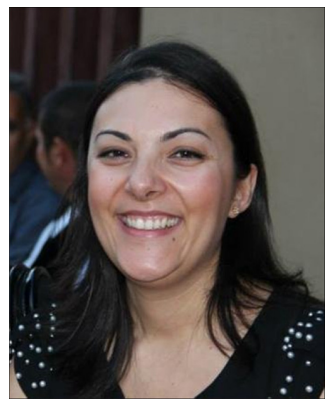

Sara Dessì received her degree in Environmental Engineering in 2013. She's currently working in an Engineering enterprise. 